\title{
Del silencio a la narración de mujeres en pueblos originarios, historias de violación"
}

\author{
From silence to the narration of women in indigenous peoples, Stories of rape
}

\author{
ALBA HORTENCIA GONZÁLEZ REYES \\ Universidad Veracruzana (México) \\ https://orcid.org/0000-0003-0928-0611 \\ alba.h.glez.r@gmail.com
}

\begin{abstract}
RESUMEN
Los relatos de mujeres sobre la traumática experiencia de violencia sexual en su infancia, forman parte del género biográfico de ancianas, mujeres adultas y jóvenes en pueblos originarios del centro norte del estado de Veracruz, México. La violación como trágica herencia interseccional que enmascara vicios privados con virtudes públicas de un deber ser femenino según marca la tradición cultural. Como orientación de sentido se propone en este escrito que, las historias de vida en espacios interculturales son hechos cotidianos que fortalecen una historia de normalización de una sexualidad violenta hacia niñas que legitima prácticas represoras y el silencio social. Género es la herramienta analítica en la historia social que nos permite el examen de las narrativas de historias de vida engarzadas por la impunidad y la violencia, bajo una tolerancia difusa de las normativas tradicionales y gubernamentales.
\end{abstract}

Palabras clave: Biografía, género, historias de violencia sexual, normativas y tradición.

\section{SUMMARY}

The stories of women about the traumatic experience of sexual violence in their childhood, are part of the biographical gender of old women, adult women and young people in native towns of the northern center of the state of Veracruz, Mexico. Rape as a tragic intersectional heritage that masks private vices with public virtues of a duty to be feminine according to the cultural tradition. As a sense orientation, it is proposed in this paper that, the stories of life in intercultural spaces are daily events that strengthen a history of normalization of a violent sexuality towards girls that legitimizes repressive practices and social silence. Gender is the analytical tool in social history that allows us to examine the narratives of life stories enshrined in impunity and violence, under a diffuse tolerance of traditional and governmental regulations.

Keywords: Biography, gender, stories about sexual violence, regulations and tradition.

Pertenece al Sistema Nacional de Investigadores Nivel I; al Núcleo Académico de UV-C.A. 301 Estudios Socioculturales. Este artículo forma parte del trabajo teórico realizado durante la estancia sabática en el Centro de Investigaciones y Estudios Superiores en Antropología Social, ciudad de México (CIESAS-CdMx) (CIESAS-CdMx) bajo la supervisión de la Dra. Patricia Ravelo Blancas entre agosto 2018 y julio 2019. 


\section{INICIO}

La República Mexicana ingresó al nuevo milenio con graves violaciones a los derechos humanos, de manera específica en los derechos sexuales y reproductivos de las mujeres y niñas. A dos décadas del siglo XXI se mantiene como uno de los grandes problemas que grupos feministas -activistas, académicas, funcionarias, organizaciones civiles- tiene en la agenda con un trabajo sostenido para atender y prevenir la violencia hacia las mujeres. Las violencias a las mujeres pueden entenderse en el marco de un ordenamiento histórico cultural androcéntrico sostenido a través de las representaciones sociales, los códigos normativos y las percepciones subjetivas.

Las experiencias de vida ponen en ejercicio posiciones de poder que, aún hoy en día, refuerzan la primacía de los varones, los posiciona de manera jerárquica respecto a otras personas; pactos patriarcales que consisten en establecer alianzas en donde las mujeres no participan como sujetas activas en la negociación. Estos pactos patriarcales son interculturales, interraciales e interclasistas. (Amorós, 1992). Tovar y Tena suman la idea de que en estos pactos patriarcales «se encuentran los referentes al control de la sexualidad de las mujeres, a la división sexual del trabajo, a la violencia y a la propiedad, nodos de desigualdad con mayor impacto en la vida de las mujeres indígenas〉>. (2017: 41).

En México, la violencia de género y la violencia sexual han estado al centro de los debates nacionales. Los activismos feministas tienen trabajo sostenido entre las diversas fuerzas políticas con las agendas para atender y prevenir la violencia hacia las mujeres. Se han aprobado diversos estatutos y leyes para la tención a las mujeres. En 2007 fue aprobada la Ley General de Acceso de las Mujeres a una Vida Libre de Violencia publicada, y en 2008 la Ley de Acceso de las Mujeres a una Vida Libre de Violencia para el Estado de Veracruz.

Entre 2013 y 2015 la labor de activistas veracruzana,s analizando las cifras de incidencia delictiva particularmente de feminicidios con la base de datos del Instituto Veracruzano de las Mujeres (IVM), el monitoreo de medios de comunicación generado por el Centro de Estudios de Género Universidad Veracruzana, y los datos reportados por el Secretariado Ejecutivo del Sistema Nacional de Seguridad Pública, dan cuenta de la brutal realidad que viven mujeres en este estado de la república mexicana (Guerra Osorno, 2019: 13)

En noviembre de 2016 Secretaría de Gobernación a nivel Federal con el Gobierno del Estado de Veracruz declaran la Alerta de Violencia de Género contra las Mujeres y Niñas, por violencia feminicida, en los municipios de Boca del Río, Coatzacoalcos, Córdoba, Las Choapas, Martínez de la Torre, Minatitlán, Orizaba, Poza Rica, Tuxpan, Veracruz y Xalapa. El trabajo de académicas y activistas feministas se sostuvo y en diciembre 2017 la Secretaría de Gobernación declara la segunda Alerta de Violencia de Género contra las Mujeres por agravio comparado en el estado de Veracruz, estrechamente relacionada con los derechos sexuales y reproductivos de mujeres y niñas. Y para el 25 de enero de 2019 , 
el gobernador del estado de Veracruz, hizo pública la Estrategia de Cero Tolerancia a la Violencia contra las Mujeres y las Niñas en Veracruz. Podría decirse que en Veracruz los marco legales de atención a víctimas de violencia sexual ha resuelto el problema, pero lejos estamos de solucionarlo.

\section{LA VIOLENCIA SEXUAL, UN PROBLEMA SOCIO-HISTÓRICO DE INTERSECCIONALIDAD}

A pesar de la generación de normativas contemporáneas para atención a niñas para evitar la violencia sexual sobre sus cuerpos, la Organización para la Cooperación y Desarrollo Económicos informó que en 2017 México encabezaba la lista de los países miembros con la más alta tasa de fecundidad adolescente y que la edad promedio de inicio de la vida sexual es de entre 12 y 17 años. El estado de Veracruz ocupó el segundo lugar nacional en embarazos en niñas y adolescentes en 2017. (Esteva, 2019: 42).

Esteva menciona que un gran porcentaje de los embarazos en niñas entre los 10 y 14 años son producto de violencia sexual, otro porcentaje aún mayor indica que el agresor de estas niñas se encuentra en su mismo círculo familiar (padres, padrastros, abuelos, tíos), es decir, el principal agresor está en casa (2019: 43). Por estudios histórico antropológicos el problema tiene arraigo en comunidades rurales e indígenas; no obstante, el problema guarda discrecionalidad. Así, las expresiones de violencia sexual a niñas en el estado de Veracruz precisa un análisis, para comprender que estos hechos pertenecen a un marco histórico de violencia estructural.

Para entender el acto traumático de la violencia sexual experimentado en cuerpos infantiles con ascendencia indígena es necesario utilizar la categoría de interseccionalidad que se enlaza con estos relatos. Obligado es mencionar a Kemberle Crenshaw (1989) para precisar que interseccionalidad es una clase definida de discriminación que interactúa con otras maneras segregación como son la exclusión, la marginación por la precisa interacción de raza o etnia, género, pobreza que reproduce la desigualdad. Se pone en foco la interseccionalidad en el problema de la violencia sexual a mujeres indígenas que, aun perteneciendo a diferentes generaciones, quedan atrapadas en dos esferas normativas punitivas: la de usos y costumbres con sanciones morales simbólicas y la normativa jurídica con un alcance correctivo limitado y con clara desventaja para ellas.

La perspectiva teórico-metodológica de la interseccionalidad en Latinoamérica y que aplica en espacios de pueblos originarios busca dar cuenta de la percepción cubierta de las relaciones de poder, reconoce las intersecciones y la posibilidad de denuncia sobre los abusos sexuales perpetrados a las mujeres indígenas, imprimiendo la vulnerabilidad que genera los contextos por su condición étnico-racial y de género (Viveros Viyoga, 2016: 4).

Es con Patricia Hill Collins (2000), que la interseccionalidad otorga una orientación para entender la dinámica binaria de control de género en contextos indígenas, por su 
característica macro sociológica y microsociológica. Su condición macro cuando la articulación de las opresiones estructurales de desigualdad social está implicada en los sistemas de poder de producción, organización y mantenimiento de las desigualdades en las vidas individuales; por ejemplo, la condición de violencia sexual que culpabiliza a las mujeres que padecen el trauma de los actos violentos ejercidos por los varones.

La parte micro social de la interseccionalidad en mujeres y niñas indígenas se visibiliza cuando ese sistema de enclavamiento de opresión de la estructura patriarcal dominante se instala en el subconsciente de tal modo que bloquea o se les mantiene inmovilizadas; por ejemplo, la experiencia de revictimización, cuando sobre una experiencia traumática, las niñas o jóvenes mujeres repiten la experiencia de violencia sexual, o bien pudiesen quedar inmovilizadas por no saber o no poder decidir, por ejemplo interrumpir un embarazo por violación, por ser menores de edad y porque las normativas legales y familiares les prohíben tales medidas.

Para unificar el binomio macro y micro social de la interseccionalidad en el problema histórico de la violencia de género y sexual en mujeres y niñas indígenas recurrimos a Ann Laura Stoler (1995) quien explica que el cuerpo puede ser reconocido como colonizador o colonizado, dentro de un esquema binario en el que los procesos regulatorios funcionan con ese sentido simbólico de coloniaje. La sexualidad otorga mayor complejidad a este esquema binario, ya que se expande los valores de ser-deber ser cuerpo desde una ubicación de relaciones interraciales.

La relación de poder colonialista produce lo que Foulcault llamo régimen biopolítico de los cuerpos; es decir, las normativas y actos sobre los cuerpos tienen una gestión regulatoria administrativa sobre la vida de los cuerpos. En el caso de niñas indígenas, mestizas ese régimen biopolítico reproduce el sentido vertical de relaciones interraciales, alentadas por las autoridades administrativas, tanto como por los discursos racistas discriminatorios, cuando consideran a las niñas como inferiores siempre en comparación con lo que significa de ser varón y genera el desarrollo de un conjunto interno de jerarquías que corresponde a los procesos normativos. Así, un varón indígena, mestizo o europeo procederá de forma colonizante o de opresión siempre que tenga un subordinado que fue educado con esa mentalidad colonizada.

\section{EL MÉTODO BIOGRÁFICO, ALCANCES Y LÍMITES CON HISTORIAS DE VIOLENCIA SEXUAL EN CONTEXTOS INDÍGENAS Y/O MESTIZOS}

El método biográfico cabe entonces para establecer una narrativa que cuente que la violencia de género y violencia sexual devienen de una violencia estructural cuya historia no debe ser silente. Como ejercicio de aplicación se presentan cuatro casos de mujeres adultas que sufrieron de violencia sexual cuando fueron menores de edad. Ellas provienen de diferentes comunidades del centro-norte del estado de Veracruz. El contacto con ellas se sucedió entre los años 2014 y 2017, durante el proceso de trabajo de campo y los cons- 
tantes viajes por las regiones totonaca de la costa y de la sierra. El trabajo de campo se realizó durante los periodos vacacionales de verano y de invierno, porque permitía tener tiempo entre los viajes y la estancia en las comunidades. No se ofrece información precisa de nombre de comunidades y solo menciona la región; tampoco se menciona los nombres de las informantes, esto obedece a tres circunstancias que involucran la legalidad de protección a víctimas y la ética profesional en relación al tema de violencia sexual a mujeres.

En primer lugar, la Ley Federal de Protección de Datos Personales en Posesión de los Particulares que se estableció en México desde 2010, indica en su artículo 3 inciso VI referente a los datos personales sensibles: «aquellos datos personales que afecten a la esfera más íntima de su titular, o cuya utilización indebida pueda dar origen a discriminación o conlleve un riesgo grave para éste. En particular, se consideran sensibles aquellos que puedan revelar aspectos como origen racial o étnico, estado de salud presente y futuro, información genética, creencias religiosas, filosóficas y morales, afiliación sindical, opiniones políticas, preferencia sexual〉>. (2010, 2).

En segundo lugar, las informantes vivieron la experiencia traumática de violencia durante su niñez, su condición de vida en pueblos originarios y en espacios mestizos obliga la protección de su intimidad. En este sentido, la Ley de víctimas del Estado de Veracruz en el artículo 8 inciso XIX exige medidas de protección eficaces cuando su vida e integridad pudieran estar amenazadas o estén en riesgo en razón de su condición (2014: $6)$.

Existen temas de complicado tratamiento tanto en el ingreso a trabajo de campo, como en el proceso de estructurar la información que no exponga la integridad de las informantes. En el trabajo sobre violencia de género y violencia sexual es obligada una postura moral que no centre su atención en la subjetivación, sino entender los diversos tipos de violencia como «fenómenos morales sociales e históricamente ubicados, cuya construcción de la vida social hecha por sujetos situados, operan en condiciones relacionales, materiales y simbólicas, históricamente engendradas que no dependen de su voluntad y que, en gran medida, les son preexistentes〉> (Balbi, 2016: 48).

Es obligado hablar del conocimiento implica hacer referencia a la operación de estructuras de percepción socialmente constituidas; pero sobre todo es importante hablar sobre la biografía de los casos de violencia en el marco de los derechos humanos y la protección a víctimas. Es necesario no confundir la narrativa de los testimonios con una romántica interpretación "positivista, indigenista culturalista que poco tenga que ver con la realidad de las comunidades indígenas en México", sino con la exposición de marginación, discriminación y explotación de las mujeres indígenas (Suárez Ávila, 2019: 59).

Bajo esta condición ética es también importante mencionar al silencio como una condición discursiva de control en el comportamiento social (Stoler 1995, Foucault 2004). En contraparte, el trabajo colaborativo entre las participantes y la investigadora, ofrece la oportunidad de conocer que el problema de violencia sexual tiene una historia. 


\section{REFLEXIVIDAD PARA HISTORIAS VIOLENTAS SOBRE MUJERES INDÍGENAS}

Al momento de las entrevistas, la primera una anciana contaba con noventa y cuatro años, de la zona centro del estado de Veracruz de una población mestiza limítrofe entre el estado de Puebla y el estado de Veracruz, cuya tradición étnica es nahua. La segunda mujer informante de setenta años, del norte del estado de Veracruz indígena totonaca, migrante de su comunidad a la ciudad de Papantla, Veracruz, después a la ciudad de Xalapa, Veracruz. La tercera señora informante de treinta y dos años oriunda de la costa de Oaxaca con ascendencia mulata, migrante a la ciudad de Papantla, Veracruz, y la última joven informante de diecisiete años de edad de la región del Totonacapan de la Sierra.

Un saber personal de mujeres, hecho narrativa para prestar especial atención a la profunda comprensión de la experiencia humana, para resaltar por una parte la escritura como mediadora entre la reflexión y la acción; por otra, la anécdota como instrumento metodológico para hacer comprensible alguna noción que fácil pudiera escapar. Cobijarse bajo métodos y técnicas de investigación social que acepta desde la acción significativa: el habla, las creencias, la tradición oral, el ritual y sus símbolos como un corpus, un conjunto potencialmente significativo, discursivo, performativo (Clifford, 2008, 156), para narrar algo sobre la verdad, es el principio de la antropología reflexiva, la historia social y la sociología reflexiva.

Con esta propuesta en que la realidad puede ser examinada como un texto, puede ilustrar que los hechos y verdades se relacionan íntimamente a vocabularios y paradigmas diversos para representarlos, explicarlos en el proceso de investigación, desde la concienciación del problema, orientándolo hacia una utilidad como herramienta de investigación narrativa que procura el conocimiento sobre la situación de inicio. Siguiendo a Gadamer, se trata de un giro hermenéutico, en el que el sujeto femenino surge como autor y productor de un saber desde una experiencia traumática; pero, en vez de silenciar su voz, como era la norma, se deja escuchar en su pleno derecho de exigir ser escuchada.

En ese sentido Merleau-Ponty en su Fenomenología de la percepción (1994) convoca a mirar los cuerpos no sólo como estructuras físicas, sino como estructuras vividas, como cuencos llenos de experiencias de vida. Lo fenomenológico para promover las posibilidades transformadoras de la experiencia humana y también de la cultura científica. Esta orientación pragmática al decir de Varela, la ciencia avanza gracias a su vínculo pragmático con el mundo fenoménico y esa cercanía convalida su eficacia (2011: 21).

La biografía como « género histórico-literario específico en que un investigador "reconstruye" una trayectoria individual sobre la base de documentación preferentemente escrita y con el auxilio eventual de fuentes orales» (Pujadas, 2000: 136). La biografía como método de la investigación narrativa, incluye relatos de vida cuya especificidad consiste en narrar historias tal como son contadas por las narradoras, pero que pueden ser escritas desde lo etic: «descripciones desde fuera que se redactan en tercera persona 
y tienen un carácter objetivista; y lo emic, descripciones desde dentro que se redactan en primera persona y tienen carácter fenomenológico»> (Caparrós y Raya, 2015: 241).

La crítica feminista ha recurrido a la narrativa como uno de sus estilos de escritura y método de investigación con una valoración epistémica ambivalente y tensa entre los estilos contrapuestos de la ficción y la ciencia. Colonzi, Hasicic, Urtazún (2014), Arvisú Juárez (2016) Santesmases, Cabré i Pairet, Ortiz Gómez (2017) son autoras que nos ofrecen sus propuestas sobre la biografía desde la mirada de género. En México, Ana Lau Jaiven nos recuerda que la nueva visión historiográfica propone incluir la desigualdad, el proceso de exclusión y discriminación en el análisis de la diferencia de los géneros (2015: 24). Teresa de Lauretis también ofrece aportes especialmente importantes por la narrativa historiográfica en relación a la pluralidad de situaciones y múltiples realidades de interseccionalidad: representar y experimentar la clase, la etnia, la sexualidad.

Para construir un marco teórico que refiera a la violencia de género, violencia sexual entre la normatividad legal, las prácticas efectivas en contextos indígenas las dos fuentes de información complementarias son los expedientes judiciales y las descripciones etnográficas. Victoria Chenaut investigadora que desde la antropología jurídica nos da luz sobre $<$ los valores morales, pero suponiendo que las cuestiones que giran alrededor del sexo y la familia han sido las que deben haber cambiado más lentamente, por pertenecer al aspecto más privado de la vida en sociedad» (1997: 133).

Con Chenaut resulta claro que, tanto para los totonacas como para los mestizos, apoyados en la costumbre o en la ley, la castidad de las jóvenes doncellas es un bien que hay que defender celosamente. «Su pérdida no sólo es una vergüenza para los hombres de su casa, sino un 'daño moral irreparable'. Entre los totonacas, significa que la joven pierde para siempre la posibilidad de realizar una boda tradicional, haya mediado o no su voluntad, quedando condenada a la unión libre»>. (1997: 134)

Baitenmann, Chenaut, Varley Ann, nos muestran que otra vía de análisis para la investigación histórica sobre género en espacios multiculturales son las diferencias regionales y la operación del derecho en la práctica. Por ejemplo, apenas en la década de los noventa del siglo XX que la violencia, antes considerada un asunto privado, se convirtió en un problema social y público. Asimismo, que la violencia doméstica hacia las mujeres constituye una parte integral de las relaciones de poder, basadas en el género y la jerarquía que prevalece en las familias indígenas mexicanas (2010: 49, 62)

Los estudios sobre género y violencia hacia las mujeres, jóvenes y niñas en contextos de pueblos originarios ofrecen una base para entender la biografía de las cuatro mujeres entrevistadas que fueron víctimas de violencia sexual. Es necesario sumar que las mujeres participantes dejaron el silencio, para colocarse en una postura de personas activas capaz de reflexionar y empezar el camino de decidir por su propia realidad; las más jóvenes tomaron conciencia sobre sus derechos y poder abonar a las nuevas generaciones la posibilidad de una vida libre de violencia. 


\title{
CUATRO RELATOS DE VIDAS ENGARZADAS POR LA VIOLENCIA SEXUAL
}

Josefa N. A los trece años de edad, ella vivía en un pueblo de la montaña veracruzana, en el seno de una familia de comerciantes.

\begin{abstract}
Mi padre comercializaba en una recua de mulas, maíz y frijol en las rancherías de aquí cerquita. Mi tata tenía un compadre que venía mucho a visitarlo a la casa. Un día, ya de tarde por las fechas de las fiestas del Santo Patrón, fui a cortar duraznos y peras al solar trasero de la casa. Mi mamacita se había ido al rosario y mi tata estaba en los ranchos. Que llega ese hombre y que me jala, ya nunca más le dije padrino. Yo no dije nada a nadie por tanta vergüenza que yo tenía. Pero desde entonces yo ando muy enojada por eso, porque me deshonró. Nunca volví a tener una risa en mi cara, pa'que. (Entrevista a la señora Josefa $\mathrm{N}$ de la montaña veracruzana realizada por Alba H. González Reyes, 19 de diciembre 2014)
\end{abstract}

El agreste ataque tuvo consecuencias, la niña quedó embarazada. Con fuertes estructuras tradicionales de catolicismo y de parentesco espiritual, la regulación social con base en la obediencia de no contravenir el tabú del incesto se había roto. El violador estaba casado y tenía una alianza de parentesco con el padre de la víctima: el compadrazgo. La única posibilidad de resarcir el daño fue casar a la niña con el sobrino del atacante.

Yo me casé con Herminio porque me dijo mi tata era lo que convenía. El primer parto fue una niña y el la registró como su hija, después tuvimos tres hijos y tres hijas más; pero, nunca tuvimos un matrimonio como Dios manda. Él casi no vivía en casa, se pasaba el tiempo con su mamá y a veces solo llegaba para darme dinero y dormir una que otra noche conmigo. Su mamá nunca quiso que yo pisara su casa, decía que yo estaba manchada con el pecado. Lo único que agradezco es que en el pueblo no se supo nada de nada. (Entrevista a la señora Josefa $\mathrm{N}$ de la montaña veracruzana realizada por Alba H. González Reyes, 19 de diciembre 2014)

El parentesco espiritual se refiere al enlace de parentesco político entre familias por el vínculo del bautismo, quedando proscrito el matrimonio entre padrinos/ahijadas, madrinas/ahijados y entre compadres. Loa padres espirituales deben, según la tradición católica, cuidar de los hijos espirituales, y cuando ancianos las/los ahijados deben cuidar de sus padres espirituales.

Historias de la vida privada y de los silencios que se guardan tras cuatro paredes, custodiando los principios de la cultura del honor. Como escribe Georges Vigarello (1999:16) la violación es un acto de violencia sexual que agrede, lastima el cuerpo de las víctimas, pero, también es una violencia psíquica que impone y sella la imagen de la falta y del pecado. La violación, nos recuerda Vigarello, es una violencia antigua que se comprende, juzga y condena, pero lleva intrínseco el sentido ambivalente de la indulgencia y la represión. Si de inicio indigna, pero en breve se va olvidando para dar paso a la trivialidad. 
Nunca nadie sabe porque siempre estaba enojada, nunca nadie entendía que la muina no me dejaba y me hacía estallar. Odio las cosas de la vida, me molestaban los ruidos que hacían los niños, mis hijos de chiquitos y luego los nietos, ya los bisnietos son diferentes, no les hago tanto caso ... A mis hijas y a mis hijos no les busqué padrinos, puras madrinas, señoritas ancianas que no se casaron, solo yo sabía mi cuento. A mis hijas siempre las tuve a raya, no las dejaba que fueran solas a ninguna parte. Si no entendían las tundía a palos, si no por la buena por la mala. Ya cuando se casaron les aconsejé que se fijaran bien a quien invitaban a su casa. También que obedecieran a la suegra pa'que no tuvieran altercados con el marido. (Entrevista a la señora Josefa $\mathrm{N}$ de la montaña veracruzana realizada por Alba H. González Reyes, 20 de diciembre 2014)

Cuando sucede una violación las acciones violentas, pasan a una segunda fase de sorpresa, indignación, con el tiempo se difumina hasta llegar a una callada tolerancia, momento en el que se empieza a dudar de la víctima como posible responsable del acto violento. Es lo que Vigarello (1999) denomina tolerancia difusa.

Xanath N. De origen indígena totonaca, se quedó huérfana a muy temprana edad, primero su madre, y a los 11 años su padre falleció. Solo tenía un hermano que la golpeaba por cualquier pretexto:

Yo quedé solita muy chiquilla. Mi hermano me golpeaba con riatas o con palos, lo primero que se encontraba. A cada rato me pegaba. Descansaba cuando él no estaba, pero cuando llegaba salía al patio para esconderme con las gallinas. Si no se emborrachaba eran más llevaderos los días; mta, pero cuando llegaba briago, golpiza segura, así pasé el primer año. Poquito después que cumplí doce años, llegó borracho y me dio una tunda con la cuarta del machete, que agarra una cadena y me amarra a un árbol de cedro bien cerca de un hormiguero. Así me quedé toda la noche y al día siguiente. Con las hormigas en el cuerpo y con sed por el calor, una vecina me encontró, se apiadó de mí y me desató. Yo corrí al río para quitarme las hormigas y después que me voy caminando a Papantla huyendo de mi hermano, no quería que me volviera a golpear. Así chiquilla y flaca como estaba llegué a Papantla y viví así pidiendo limosna, ayudando a barrer o lavando trastes. Así pasé algunos meses en una fonda de antojitos, hasta que conocí al señor que fue mi marido. El tenía cuarenta años, yo doce. Me invitaba a comer y en veces me preguntaba por mis papacitos, por mi familia. Cuando le platiqué que mi mamá y mi papá eran finados y mi hermano golpeador, me decía que fuera a conocer a su mamá, ella me iba a cuidar y a querer como una madre. Yo le creí, y una semana después de insiste, insiste y insiste me llevó para Gutiérrez Zamora. Ya cuando llegamos a su casa la señora me bañó, me cambió de ropa y me dio de comer. Toda la tarde jugué en el patio, me sentía contenta. Para cuando estábamos cenando me dice la señora: "al rato que llegue m’ijo tú te vas a ir a dormir con él porque así debe ser. Si acaso tienes dolor, no te preocupes, es normal y luego yo te voy a cuidar".

Yo no sabía de qué se trataba, así chiquilla como estaba no sabía de hombre ni de nada de eso. Le obedecí a la señora. No pensé que me iba a quedar en esa casa para siempre. Tampoco que me iba a casar. Y pues ya después que sucedió lo que tenía que pasar, 
yo estaba muy asustada y lloraba de dolor y de miedo. Mi señor entonces se levantó de la cama fue por su mamá y ella me dijo que era natural sentir así, con el tiempo ya no iba a sufrir. Pasé una semana en cama por el dolor y el sangrado [...] Después de ese día ya no salí de la casa, si no era con la señora o con mi señor. A poco tiempo supe que era tener regla (menstruación), que solo llegó una vez porque luego me quedé embarazada. Y por eso fue que me casé por la iglesia y por lo civil con él. (Entrevista a la señora Xanath $\mathrm{N}$ de la región del Totonacapan de la costa realizada por Alba H. González Reyes, 3 de julio 2015)

En la historia del derecho, el artículo 744 del Código Penal del Estado de Veracruz de 1936 se menciona el delito de rapto, donde el varón incurría en daño por la finalidad de satisfacer algún deseo erótico-sexual. Y se salvaba la ofensa, a través del casamiento del violador con la agraviada. Este delito se perseguía por querella, lo que indica que la mujer o niña se encontraba en pleno estado de indefensión jurídica. En referencia al delito de rapto - en la actualidad derogado-, una forma de sancionar era reparar la falta, por lo que si los padres estaban de acuerdo se procedía a la unión matrimonial entre la víctima y su violador como un tipo de reparación.

Chanut menciona que « la protección de la virtud femenina es, obligación del padre o de los hermanos de la joven; a falta de ellos, es la madre quien asume el deber y la responsabilidad de una querella legal»>. (1997: 135). En el caso de Xanath no tenía a personas adultas que cuidasen de ella. Así que la pobreza, la orfandad, la falta de apoyo o ausencia de familia, el vacío de responsabilidad del estado, infringen menor gravedad al delito y mayor impunidad a la gravedad del crimen. Xanath no supo que además de rapto, fue víctima de engaño o estafa. En su sentido legal jurídico el estupro aplica a un tipo de delito sexual. Para que el estupro se considere delito es necesario que la persona sea adulta y que su víctima sea un menor de edad, así el caso de Xanath.

Después, Dios me regaló nueve hijos, siete varones y dos mujeres. Yo no me quejo, mi esposo nunca me pegó y quién me regañaba si hacía algo malo era su mamá. Yo lo atendí hasta que murió a los setenta años, yo me quedé con su mamá y cuando ella murió salí de su casa porque sus otros hijos me corrieron. Pero ya mis hijos estaban grandes, unos ya se habían casado y otros se fueron para los Estados Unidos. Yo me fui para Puebla un tiempo y luego para Xalapa. Aquí vivo con uno de mis hijos y dos nietos. Vendo galletas de piloncillo y de maíz. Nos va bien y estamos juntos. (Entrevista a la señora Xanath $\mathrm{N}$ de la región del Totonacapan de la costa realizada por Alba H. González Reyes, 11 de julio 2015)

En el mismo código, el delito de estupro amplió el rango de edad de mayor de catorce a menor de dieciocho años. Al analizar el Capítulo IV del Código se observa que también existe un vacío jurídico respecto al agravante relacionado con la edad del agresor, pues no indica la sanción para aquellos victimarios que tengan una diferencia de edad con la víctima mayor de siete años. En el caso de la informante su esposo le superaba la edad con treinta años. 
Juanita N. Una mujer adulta con un carácter afable y solidario. Ella fue víctima de violación, además de contraer VIH.

Corría el año 1998 yo tenía catorce años y vivía con mis padres. Mi pá tomaba, bueno toma mucho, ahora menos porque está enfermo, pero cuando yo lo recuerdo de niña, después de regresar de su trabajo como obrero, pasaba por sus cervezas o su aguardiente. Mi mamá, pobrecita, siempre callada y calmada. Quien se enojaba era mi papá. Yo no les hacía mucho caso, cuando peleaban me salía a la calle para jugar con mis vecinos y mis hermanos. De donde vengo hace mucho calor, no se aguanta estar dentro de las casas. La gente acostumbraba sentarse en el piso de las banquetas para pasar un rato por la tarde. De dónde vengo es un pueblo chico donde todos se conocen.

Después de la primaria ya no seguí estudiando, tenía que trabajar para ayudarle a mi mamá a mantener la casa y los hijos chiquitos, pos mi papá todo se lo tomaba y se lo jugaba. Así conocí quien sería el padre de mi hija. Él tenía veintiocho años y trabajaba en el marcado, cerca del restaurante donde yo me pasaba el día haciendo comida y lavando platos. Me decía cosas bonitas, mis amigas me decían que estaba muy grande para mí. Aunque chiquilla ya tenía cuerpo como de una joven veinte años. Muy frondosa. Me contaba la gente que era casado y de 'fácil bragueta', enagua que veía enagua que quería. Pero yo estaba muy ilusionada. Ya ve que una de chamaca todo es color de rosa, nada de maldá, ni de malos pensamientos.

El caso es que le hice caso, me hice novia de él, salíamos por la tarde y se la pasaba sentado en la banqueta de mi casa. Así pasaron meses y yo no veía nada que fuera malo en él. Cuando cumplí catorce años me llevó un pastelito y unos aretes de regalo. Era como quien dice mii primer amor. Después de mi cumpleaños me invitó a donde vivía y yo acepté. Me invitó cervezas y yo me emborraché, cuando me sentí borracha le dije que mejor me iba y no me dejó salir. Me resistí, pero fue peor, me pegó en los brazos, me empujó y caí al suelo. Me gritaba diciendo que nadie me iba a creer porque yo solita acepté llegar a su cuarto. Lloraba y le decía que me dejara salir, después de eso no recuerdo mucho que sucedió, en ocasiones me viene imágenes a la memoria donde estoy hincada y él a lado mío, con un cuchillo en la mano.

No recuerdo más que me desperté al día siguiente, me sentía mareada y me dolía la cabeza. Cuando volví a mi casa mi mamá estaba asustada por mí, no le dije nada porque no recordaba que había sucedido. Mi padre ni cuenta se dio, estaba borracho. Después de esa ocasión me agarró la medida y a la fuerza me llevaba a su cuarto. Yo no puse resistencia, una porque lo quería y otra porque pensaba no importaba ya nada, suponía que me amaba, aún con el maltrato que me daba con jaloneos, golpes en los brazos y patadas en las piernas. Siempre me pegaba en zonas del cuerpo donde no se vieran los moretones. A los meses me di cuenta que estaba embarazada. Cuando lo supo, me confesó que sí estaba casado. Mi hija nació dos meses antes que cumpliera quince años. Ese fue mi regalo y mi fiesta que con tanto anhelo había soñado.

Luego él volvió para conocer a la bebé y continuamos juntos un año más. Mejor decidió largarse a Estados Unidos y ya no lo vi más. Después por unos estudios que me hice salió que era cero positiva. Hace unos cinco años me enteré que él falleció solo y sin cuidados. Antes se jactaba de que tenía más de 15 hijos, pero murió como un perro. Yo me cuido mucho, tengo atención médica, por fortuna mi hija está sana, ella estudia 
y trabaja. Creo que mi historia la mantiene para no repetir. A veces me da tristeza porque no tuve la oportunidad de estudiar. Esta condición mía me pone a pensar que ahora soy yo quien debe cuidarse y no permitir abusos de nadie. No me gusta pensar mucho en futuro, me angustia saber que podría tener un final, así solita y sin apoyo, luego me conformo al ver que tengo personas a mi lado que si me orientan y me quedo tranquila por el tiempo que Dios me dé en este mundo. (Entrevista a la señora Juanita $\mathrm{N}$ de la región del Totonacapan de la costa realizada por Alba H. González Reyes, 8 de julio 2016)

En ese mismo año de 1998, durante el mes de septiembre cuando se expide la Ley 104, Ley de Asistencia y Prevención de la Violencia Familiar en el Estado de Veracruz se realiza una evaluación con críticas y sugerencias de dicho documento por parte de los grupos feministas y Organizaciones Civiles, quienes se concentraron en señalar la exclusión e invisibilidad de las mujeres y las niñas. Por ejemplo, en su capítulo I, artículo 2, inciso III la violencia se consideraba solo maltrato y no visibilizaba a los sujetos de mayor vulnerabilidad: mujeres y niñas.

Tampoco existía delito que perseguir, se hablaba solo de maltrato, una categoría sin efecto jurídico ni sanciones. Maltrato físico: « entendiéndose todo acto de agresión intencional repetitivo en el que se utilice alguna parte del cuerpo, algún objeto, arma o substancia para sujetar, inmovilizar o causar daño a la integridad física del otro, encaminado hacia su sometimiento o control; b) Maltrato psico-emocional: entendiéndose el patrón de conducta consistente en actos u omisiones repetitivas cuyas formas de expresión pueden consistir en prohibiciones, coacciones, condicionamientos, intimidaciones, desprecios, actitudes devaluatorias de abandono o cualquier otro que provoquen en quien las recibe, deterioro, disminución o afectación de la autoestima〉 (Ley de Asistencia y Prevención de la Violencia Familiar en el Estado de Veracruz, 1998).

Esta Ley tampoco consideraba como delito la violencia física, emocional y violencia sexual a menores y se mencionan únicamente como maltrato. « Todo acto que se compruebe que ha sido realizado con la intención de causar un daño moral a un menor de edad, será considerado maltrato emocional en los términos de este artículo, aunque se argumente como justificación la educación y formación del menor. Maltrato sexual: entendiéndose por tal los actos u omisiones reiterados que infligen burla y humillación de la sexualidad, así como formas de expresión tendientes a negar las necesidades sexoafectivas, inducir a la realización de prácticas sexuales no deseadas, la celotipia para el control, manipulación o dominio de la pareja, y que generen daños» (Ley de Asistencia y Prevención de la Violencia Familiar en el Estado de Veracruz, 1998).

La Ley 104 fue modificada mediante el decreto Número 258, publicado en la gaceta oficial número 154, con fecha del 15 de agosto de 2005. Se reformaron las Fracciones II y III del artículo 2 y mantuvo el nombre de Ley de Asistencia y Prevención de la Violencia Familiar en el Estado de Veracruz, pero sin modificar la categoría de maltrato por la de violencia, ni su condición jurídica de delito. 
Una última reforma tuvo la Ley de Asistencia y Prevención de la Violencia Familiar en el Estado de Veracruz, mediante el decreto Número 884, publicado en la gaceta oficial número Extraordinario 214, con la fecha 19 de julio de 2007, en la fracción VIII del artículo 7, en la que se dictaba: «Promover programas educativos en las zonas urbanas, rurales e indígenas -éstas en su lengua-, para la prevención de la violencia familiar con las instancias competentes, y establecer un programa de capacitación para maestro del Sistema Educativo Estatal, para la detección y apoyo a casos de violencia familiar entre las niñas y los niños que cursan la educación básica〉 (Ley de Asistencia y Prevención de la Violencia Familiar en el Estado de Veracruz, 2007).

Con los vacíos de vigilancia y de interés por parte de estado, este tipo de historias se habrían se seguir repitiendo.

María N. Pertenece a una generación de jóvenes denominado millennials, que fluctúan entre los 16 y 36 años de edad. Solo que ella proviene de un contexto de pueblos originarios con rígidas costumbres que confirman el sentido de interseccionalidad, pero con un sentido distinto en su horizonte cultural. Como muchas jóvenes de comunidades indígenas mantenía las reglas que sus padres le enseñaron. Estudió hasta segundo grado de secundaria, pero decidió casarse antes de cumplir los quince años. El joven marido no más grande que ella la pidió en matrimonio y cumplieron la exigencia de un matrimonio temprano. La aventura de la migración internacional impulsó a un grupo de jóvenes varones probar suerte en "el otro lado", llamando así a Estados Unidos. Así que sin pensarlo mucho tomaron sus pequeñas maletas y marcharon hacia Reynosa Tamaulipas y esperar a cruzar para Texas. Las redes de solidaridad migrante tienen sus estrategias para conseguir empleos y vivienda en Estados Unidos. María se quedó en su comunidad, embarazada y como dictan las normas consuetudinarias, bajo el cuidado de sus suegros. A los quince años tuvo a su hija, pero en el periodo de la cuarentena, el suegro intentó violarla. Su madre fue en su rescate para llevarla a la casa materna. Doña Rafaela, la madre contaba en voz baja:

Y una vez que estuvo aquí ya conmigo, que viene varias veces bien borracho a patear las puertas, exigiendo que yo le abriera y la otra que María se fuera pa'allá para su casa, que es donde debe estar, porque es mujer casada. Como mi marido también se fue para el norte, no teníamos defensa, el único varón en esta casa, mire usted es m’ijo todavía chiquillo, apenas tiene 12 años. No puede ponerse con un hombre de cuarenta años, borracho y con machete.

No le hicimos caso y, a otro día que va bien enojado y le llama por teléfono a su hijo, diciendo que María ni siquiera esperó la cuarentena y ya andaba de "loca”. Que había abandonado la casa de respeto de sus suegros y habían manchado la honra de su marido ausente. El muchacho llamó a mi'ija diciendo que volviera a casa del suegro para no deshonrar su nombre ante la comunidad. María se atrevió y le contó el por qué se había juido de esa casa. Las palabras de la esposa frente a la palabra del suegro, quien salió perdiendo fue María (Entrevista realizada a Doña Rafaela N, madre de María, 2 de julio 2016). 
El joven marido, siguió las reglas impuestas por la comunidad y dio crédito a la voz jerárquica de su padre. Pero María y Rafaela se mantuvieron firmes en la decisión de no permitir abusos por parte del suegro.

Cabe una interpretación desde la antropología con María Eugenia D’Abeterre Buznego (2000: 114), quien, siguiendo a François Héritier (1994) nos habla de las prohibiciones con los parientes espirituales y la proscripción de que pesa sobre los afines (cuñados, cuñadas, suegros, suegras), « se inscribe dentro de la lógica que rige al tabú del incesto de "segundo tipo" [...] puede decirse que la reprobación moral de las relaciones sexuales entre las categorías de parientes podría considerar simbólicamente idénticas al padre y al hermano del esposo de ego (suegro y cuñado)〉>.

María y su madre supieron encarar con responsabilidad la decisión de no permitir un acto de violencia sobre la joven esposa. El marido decidió abandonar a la chica y a su pequeña hija, con el castigo de la comunidad sobre los hombros de la joven, María tuvo que migrar a la ciudad de México para trabajar y mantener a la niña. El destierro fue e resultado del hostigamiento de la comunidad hacia María. En las dos primeras historias, no hubo, en términos legales, forma alguna de defender a las niñas víctimas de violencia. En el tercer caso tampoco se pudo acceder a la ley para defender a la menor de edad, y en el último caso, María pudo haber llevado a cabo su denuncia en defensa de su dignidad e integridad, pero no pudo hacerlo porque el peso de la ley consuetudinaria, dio mayor importancia a los argumentos de su suegro, varón jefe de familia.

Si se analiza el discurso legal, la atención a víctimas de violencia sexual el estado de Veracruz, se tipifica como delito dentro de la Ley de Acceso de las Mujeres a una Vida Libre de Violencia para el Estado de Veracruz y según las últimas reformas, confiere al < <acto que degrada o daña el cuerpo y/o la sexualidad de la víctima, que atenta contra la libertad, dignidad e integridad, como una expresión de abuso de poder que implica la supremacía sobre la mujer, al denigrarla o concebirla como objeto〉>. A su interior existen 14 variables de violencia sexual, en este escrito y para fines de contextualización de los casos a narrar, se consideran únicamente el acceso carnal violento, la violación y los tocamientos libidinosos sin consentimiento (2014: 10).

En el Código penal del Estado de Veracruz vigente y con reforma en 2014, especifica en el artículo 184 la violación «A quien por medio de la violencia física o moral tenga cópula con una persona [...] Se entiende por cópula la introducción del pene en el cuerpo de la víctima, por vía vaginal, anal u oral. También se considera que comete el delito de violación quien, por medio de la fuerza física o moral, introduzca por vía vaginal o anal cualquier objeto o parte del cuerpo distinto al pene, sin importar el sexo de la víctima〉> (Código Penal Estado de Veracruz, 2015)

En el Artículo 185, del mismo Código Penal la violación se considerará agravada, cuando concurra varios supuestos, para fines de centrar en la violencia sexual en el ámbito privado se van a considerar los siguientes:

«II. Que el responsable fuere ascendiente, descendiente, adoptante, adoptado, hermano, hermana, padrastro, madrastra o tutor de la víctima; fuere o haya sido concubina, 
concubinario, amasia, amasio o pareja sentimental del padre o de la madre de la víctima. (Con reformas al 2015) \. III. Que el responsable tenga bajo su custodia, guarda o educación a la víctima (Reforma en 2017). IV. Que se cometa por quien desempeñe un empleo, cargo o comisión públicos, o en ejercicio de una profesión, empleo o ministerio religioso, utilizando los medios o circunstancias que ello le proporciona (Reformado 2019); V. Que se obligue a la víctima a consumir, o se le suministre sin su consentimiento, drogas, estupefacientes, psicotrópicos o cualquier otra sustancia tóxica que imposibilite su defensión de manera total, parcial, momentánea o permanente (Adicionado en 2019); VI. Que el sujeto activo se aproveche de la confianza, ignorancia, extrema necesidad económica o alimentaria o subordinación de la víctima, o de la relación de superioridad o de cualquier índole que sobre ésta tenga (Adicionado en 2019). VIII. Que el responsable allane el domicilio de la víctima (Adicionado en 2019).

\section{FRENTE A LOS DISCURSOS LEGALES EN DEFENSA DE VÍCTIMAS DE VIOLENCIA ¿QUÉ SUCEDE QUÉ HACER?}

Varias justificaciones surgen para que, el proceso de ejecución de las normas legales a favor de las víctimas no se ejerza. Héctor Domínguez Ruvalcaba y Patricia Ravelo Blancas señalan la pobreza y el patriarcado como amenazas y la corrupción que acompañan a la victimización, « «desde ahí se pueden comprender las relaciones de poder en la sociedad latinoamericana actual〉 (2012: 22). Domínguez Ruvalcaba (2013) escribe que los violadores se presentan de hechos como víctimas de sus instintos, seres incapaces de controlar sus impulsos, víctimas por su condición de pobreza y hacinamiento. Los violadores se presentan como enfermos y transgresores morales, no como infractores jurídicos. Por lo tanto, la violencia queda en el marco de lo privado-moral-religioso y no como un delito público-ético-jurídico.

Empezar por reconocer que existe una diversidad cultural con horizontes históricos diversos con herencias coloniales de América Latina, incluyendo los pueblos indígenas de México (Marañon, 2014). Y desde esa realidad se planteen alternativas acordes con las características y problemas de dichos espacios/tiempos, que surjan desde la interculturalidad o la ecología de saberes.

La biografía de las mujeres entrevistadas que presentan historias de vida marcadas por el trauma de la violencia sexual, no tiene mucha diferencia con el abuso sexual de niñas en la actualidad. Las condiciones legales cambiaron; sin embargo, las prácticas de violencia sexual mantienen las agendas de las y los especialistas en la materia en las sociedades occidentales y de los pueblos originarios. Al decir de Gloria González (2019) las expresiones de la violencia sexual permanecen aún normalizadas e invisibilizadas en las sociedades patriarcales profundamente arraigadas. 


\section{CONCLUSIONES}

Cabe señalar un último dato respecto a leyes de protección a pueblos indígenas en México, que recién en 2010 que se creó la Ley de Derechos y Culturas Indígenas de Veracruz. Antes de ello «la problemática de los pueblos indígenas no figuraba en forma prioritaria en la agenda de los legisladores y que prejuicios y presiones políticas de diversa índole influyeron para que Veracruz hiciera reformas limitadas sobre este asunto»> (Chenaut, 2014:52).

Con todo lo anterior, recuperar el significado de El Contrato Sexual (Pateman, 1995) para comprender que lo público-privado no puede ser enfrascarse de manera separada ni en polaridad. Proponer la democratización de la esfera privada, pretende reivindicar la necesidad de establecer el empeño de contar la historia contemporánea de otra manera, como una historia social entre los géneros en igualdad política.

Obligatorio es, revisar logros y obstáculos de las mujeres indígenas en el ámbito del ejercicio político, los tiempos que han negociado entre lo doméstico y lo político y narrarlo (Dalton, 2012). Los obstáculos, así como las estrategias para generar opciones y ventanas de oportunidad de visibilizar a las mujeres en la esfera pública política y por supuesto, sus negociaciones con los varones para la educación responsable para con los y las niñas, una historia pendiente en los relatos de historias de vida.

Los relatos retrospectivos en prosa sobre mujeres para ocuparse de su existencia, de su subjetividad y sobre todo de la historia de su dolor no solo describe la experiencia vivida de modo directo, cabe en reflexividad acerca de las formas que su discurso también las conformó como seres femeninos con una experiencia de vida que las va transformando. Pero no es posible un cambio social en las mujeres si no hay las posibilidades de mejoramiento en la educación y en las oportunidades económicas para mujeres y varones en espacios interculturales y de pueblos originarios. 


\section{BIBLIOGRAFÍA}

Ámoros, Celia (Edit) (2000) Feminismo y Filosofía, Madrid: Editorial Síntesis.

Álvarez de Lara, R. M., Pérez Duarte y Noroña, A. (Coordinadoras). (2010). Modelos para prevenir, atender, sancionar y erradicar la violencia contra las mujeres. México: UNAM/CONACYT.

Arvesú Juárez, S. M (2016) «Los silencios en la memoria. Narrativa de la violencia sexual en la Comisión de la Verdad y Reconciliación de Perú»>. Entre Diversidades, Primavera/verano, pp. 49-77.

Baitenmann Helga, Chenaut Victoria, Varley Ann, (2010) Prácticas del Derecho en el México Contemporáneo. México: UNAM-Programa Universitario de Estudios de Género, Fondo de Desarrollo de las Naciones Unidas para la Mujeres.

Balbi, Fernando Alberto (2016) «Moral, ética y codificación en la antropología sociocultural argentina〉, Revista de Antropología, número 28, junio, Misiones Argentina: Universidad Nacional de Misiones, pp. 43-71

Caparrós Civera, N y Raya Diez E. (2015) «La otra mirada: reflexividad e investigación narrativa〉, Métodos y técnicas de investigación en trabajo social, pp- 233-252.

Chenaut, V. (1997) «Honor y ley: la mujer totonaca en el conflicto judicial en a segunda mitad del siglo XX» Soledad González Montes y Julia Tuñon (Comps) Familias y mujeres en México: del modelo a la diversidad, México: Colegio de México, pp. 111-160.

- (2011) Violencia y delitos sexuales entre los totonacas de Veracruz, México. En Chenaut, Gómez, V. \& Gómez M. \& Ortiz H. \& Sierra M. T. (Coordinadores), Justicia y diversidad en América Latina. Pueblos indígenas ante la globalización. (pp. 335-356). México: CIESAS/ FLACSO.

- (2014), Género y procesos interlegales, CIESAS/COLMICH: México.

Código Penal del Estado de Veracruz, Xalapa Veracruz 1936.

Código Civil para el Estado de Veracruz de Ignacio de la Llave. 2019. Xalapa: Gaceta Oficial.

Código Penal para el Estado Libre y Soberano de Veracruz de Ignacio de la Llave. 2014. Xalapa Veracruz: Gaceta Oficial.

Código Penal del Estado de Veracruz, Xalapa Veracruz, 1936.

Código Civil para el Estado de Veracruz de Ignacio de la Llave. 2019. Xalapa: Gaceta Oficial.

Código Penal para el Estado Libre y Soberano de Veracruz de Ignacio de la Llave. 2014. Xalapa Veracruz: Gaceta Oficial.

Collins Hill Patricia (2000) Black feminist throuht: Knowledge, consciousness and the politics of empowerment. New York: Routledge.

Crenshaw, Kimberle (1989) «Demarginalizing the Intersection of Race and Sex: A Black Feminist Critique of Antidiscrimination Doctrine, Feminist Theory and Antiracist Politics, Legal Forum», Article 8, Issue I, University of Chicago, pp. 139-166. 
Dalton, M., Aranda, J. (2012). Políticas Públicas. Oportunidades y Equidad de Género, Oaxaca: CIESAS-Pacífico Sur/CNDPI/UABJO.

D’Aubeterre Buznego, M. (2000). El pago del a novia. México, COLMICH/BUAP.

Domínguez Ruvalcaba H. (2013) De la sexualidad a la violencia de género. La modernidad y la nación en las representaciones de la masculinidad en México contemporáneo. México: CIESAS/CONACYT.

Esteva Cruz, Katya «Embarazo adolescente en Veracruz”. Estrategias de erradicación de violencia de género, contra las mujeres y las niñas». Revista del CEPREVIDE. Cultura de Paz y Derechos Humanos, Número 1, 2019, pp. 42- 45

Foucault, Michel (2004) El orden del discurso, Barcelona: Tusquets

Guerra Osorno, Marcela Dolores, «¿Cómo fueron elegidos los municipios con alerta de género?» Estrategias de erradicación de violencia de género, contra las mujeres y las niñas. Revista del CEPREVIDE. Cultura de Paz y Derechos Humanos, Número 1, 2019, pp. 5-7.

Lau Jaiven, L. (2015). «La historia de las mujeres. Una nueva corriente historiográfica». La historia de las mujeres en México, INHERM/SEP/, pp. 19-46

Ley de Asistencia y Prevención de la Violencia Familiar en el Estado de Veracruz. 1998. Xalapa, Veracruz: Gaceta Oficial

Ley de Asistencia y Prevención de la Violencia Familiar en el Estado de Veracruz, mediante el decreto Número 884, 2007. Xalapa, Veracruz: Gaceta Oficial número Extraordinario 214.

Ley de Acceso de las Mujeres a una Vida Libre de Violencia para el Estado de Veracruz. de Ignacio de la Llave. Gaceta Oficial. 2008, Tomo CLXXVIII, Núm. Ext. 65, Ley Número 235 (2014).

Ley de Asistencia y Prevención de la Violencia Familiar en el Estado de Veracruz. 1998. Xalapa, Veracruz: Gaceta Oficial. (Reformada, G.O. 19 DE JULIO DE 2007).

Ley Federal de Protección de Datos Personales en posesión de los particulares. 2010 México: Diario Oficial de la Federación.

Ley de Víctimas para el Estado de Veracruz de Ignacio De La Llave. 28 de noviembre 2014, Xalapa, Veracruz: Gaceta Oficial, Órgano del Gobierno del Estado de Veracruz.

Marañon Pimentel, B. (Coordinador) (2014). Buen vivir y descolonialidad. Crítica al desarrollo y la racionalidad instrumentales. México: UNAM.

Martínez Aranzadi, J. (2008). Introducción histórica a la antropología del parentesco. Madrid: Editorial Universitaria, Ramón Areces.

Millán, M. (Coordinadora). (2013). Más allá del feminismo: Caminos por andar, México: Red de Feminismos Descoloniales.

Ravelo Blancas, P., Domínguez Ruvalcaba, H. (Coordinadores). (2012). Diálogos Interdisciplinarios sobre Violencia Sexual. Antología. Colección Diversidad sin Violencia. México: MLLILAS/ FONCA CONACULTA/ Chicano Studies The University of Texas at El Paso, Ediciones EÓN. 
Santesmases, MJ, Cabré i Pairet, Ortiz Gómez, M.T (2017), «Feminismos biográficos: aportaciones desde la historia de la ciencia», ARENAL, 24:2; julio-diciembre 2017, 379-404.

Stoler, Ann Laura (1995) Race and the education of desire: Foucault's 'History of Sexuality' and the colonial order of things. Durham: Duke University Press.

Suárez Ávila, Paola (2015) «Los retos de la incorporación de la teoría feminista y de género en las antropologías del mundo». Los estudios de género hoy. Debates y perspectivas. México: UNAM.

Tovar-Hernández1 Deysy Margarita, Tena Guerrero Olivia (2017) «Mujeres nahuas: desapropiando la condición masculina», Revista Culturales, volumen 5 número 2 julio diciembre, pp. 39-65.

Vigarello, G. (1999) Historia de la violación. Feminismos, España: Cátedra.

Viveros Vigoya, Mara (2016) «La interseccionalidad; una aproximación situada a la dominación», Debate Feminista 52, pp. 1-17. 